\title{
Island biogeography of soil bacteria and fungi: similar patterns, but different mechanisms
}

\author{
Shao-peng $\mathrm{Li}^{1,2,3} \cdot$ Pandeng Wang $\mathbb{D}^{1,4} \cdot$ Yongjian $\mathrm{Chen}^{4} \cdot$ Maxwell C. Wilson ${ }^{5} \cdot$ Xian Yang $\mathbb{D}^{1} \cdot \mathrm{Chao}^{\mathrm{M}} \mathrm{Ma}^{6} \cdot$ \\ Jianbo $\mathrm{Lu}^{7} \cdot$ Xiao-yong $\mathrm{Chen}^{2,8} \cdot$ Jianguo $\mathrm{Wu}^{5} \cdot$ Wen-sheng Shu ${ }^{9} \cdot$ Lin Jiang $\mathbb{D}^{1}$
}

Received: 7 January 2020 / Revised: 27 February 2020 / Accepted: 2 April 2020 / Published online: 27 April 2020

(c) The Author(s) 2020. This article is published with open access

\begin{abstract}
Microbes, similar to plants and animals, exhibit biogeographic patterns. However, in contrast with the considerable knowledge on the island biogeography of higher organisms, we know little about the distribution of microorganisms within and among islands. Here, we explored insular soil bacterial and fungal biogeography and underlying mechanisms, using soil microbiota from a group of land-bridge islands as a model system. Similar to island species-area relationships observed for many macroorganisms, both island-scale bacterial and fungal diversity increased with island area; neither diversity, however, was affected by island isolation. By contrast, bacterial and fungal communities exhibited strikingly different assembly patterns within islands. The loss of bacterial diversity on smaller islands was driven primarily by the systematic decline of diversity within samples, whereas the loss of fungal diversity on smaller islands was driven primarily by the homogenization of community composition among samples. Lower soil moisture limited within-sample bacterial diversity, whereas smaller spatial distances among samples restricted among-sample fungal diversity, on smaller islands. These results indicate that among-island differences in habitat quality generate the bacterial island species-area relationship, whereas within-island dispersal limitation generates the fungal island species-area relationship. Together, our study suggests that different mechanisms underlie similar island biogeography patterns of soil bacteria and fungi.
\end{abstract}

\section{Introduction}

For centuries, islands have served as useful natural laboratories for addressing fundamental ecological and evolutionary questions [1-3]. The study of islands

Supplementary information The online version of this article (https:// doi.org/10.1038/s41396-020-0657-8) contains supplementary material, which is available to authorized users.

Wen-sheng Shu

shuws@mail.sysu.edu.cn

$\triangle$ Lin Jiang

lin.jiang@biology.gatech.edu

1 School of Biological Sciences, Georgia Institute of Technology, Atlanta, GA 30332, USA

2 Zhejiang Tiantong Forest Ecosystem National Observation and Research Station, School of Ecological and Environmental Sciences, East China Normal University, Shanghai 200241, China

3 Institute of Eco-Chongming (IEC), Shanghai 202162, China

4 School of Life Sciences \& School of Ecology, Sun Yat-sen inspired the development of the theory of island biogeography [4], and, subsequently, a large body of empirical work on the biogeography of insular plants and animals [5-8]. However, although a growing body of research shows that microorganisms have similar biogeography as higher organisms [9-14], little is known about the biogeography of island-dwelling microbes [15]. Our knowledge on microbial biogeography is almost entirely derived from studies of continuous landscapes [9, 12, 14, 16-18]

University, Guangzhou 510275, China

5 School of Life Sciences \& School of Sustainability, Arizona State University, Tempe, AZ 85287, USA

6 Anhui Province Key Lab of Farmland Ecological Conservation and Pollution Prevention, School of Resources and Envirolnment, Anhui Agricultural University, Hefei 230036, China

7 College of Life and Environmental Sciences, Hangzhou Normal University, Hangzhou 310036, China

8 Shanghai Institute of Pollution Control and Ecological Security, Shanghai 200092, China

9 School of Life Sciences, South China Normal University, Guangzhou 510631, China 
or virtual islands, such as bacteria in water-filled treeholes [19], ectomycorrhizal fungi on host plants [20, 21], microfungi in floral nectar [22], and diatoms in boreal springs [23]. However, islands differ from mainland systems in various aspects, including abiotic environmental conditions, the size of supported populations, and the extent of species dispersal, making it difficult to directly apply assembly mechanisms of communities on mainland to islands [24, 25]. Likewise, virtual islands, which are often substantially smaller than actual islands, may not necessarily replicate community assembly processes on actual islands [26, 27]. Therefore, there is a critical need to elucidate the biogeography and underlying assembly mechanisms of microbial communities for true island systems.

Understanding processes driving island biogeographical patterns has proven difficult. One reason for this difficulty is the failure to appreciate the broad spectrum of plausible mechanisms. Three main candidate mechanisms are often thought to contribute to positive island speciesarea relationships. Larger islands could harbor more species simply because of their ability to support more individuals (the sampling effect [28]). Higher species colonization rate and lower extinction rate may confer greater species diversity on larger islands (the area per se effect [28]), as predicted by the equilibrium theory of island biogeography [4]. Larger islands may also support more diverse species assemblages because they tend to contain a greater diversity of habitats (the habitat heterogeneity effect [28, 29]). However, besides these mechanisms, several other factors may also play important, but underappreciated, roles in producing species-area patterns. For example, smaller islands tend to contain disproportionally more edge habitats that experience greater levels of abiotic stress (e.g., wind turbulence, desiccation), which could result in overall lower habitat quality, and in turn, lower species diversity on smaller islands [30, 31]. Dispersal limitation, known to occur for microbial communities $[13,21]$, may not only shape communities across islands but also across localities within islands, especially for large islands where there are substantial distances among localities. Greater dispersal limitation among localities within larger islands may thus have the potential to contribute to island species-area relationships.

Here, we first propose a novel framework that helps to gain a more complete understanding of mechanisms driving insular species-area relationships. We then apply this framework to the islands of the Thousand-Island Lake in subtropical China to explore mechanisms driving soil bacterial and fungal species-area relationships on these islands. Building on previous work [28, 32, 33], this framework decomposes island-level diversity (henceforth gamma diversity) into species richness within samples (henceforth alpha diversity) and species turnover among samples (henceforth beta diversity) within islands (Fig. 1). Unlike previous work, our approach simultaneously considers common candidate mechanisms contributing to species-area relationships, as well as previously underappreciated mechanisms including difference in habitat quality among islands and dispersal limitation within islands. For example, the increased gamma diversity on larger islands, in the absence of alpha and beta diversity relationships with area, indicative of the negligible influence of the balancing between species colonization and extinction, habitat differences, or dispersal limitation on diversity within islands, would provide evidence for the importance of the sampling effect (Fig. 1a). A positive relationship between alpha, but not beta diversity, and island area would point to the importance of the area per se effect [28], as predicted by the equilibrium theory of island biogeography [4], or to improved environmental conditions favoring higher species diversity on larger islands (the habitat quality effect; Fig. 1b; [34]). On the other hand, a positive relationship between beta, but not alpha diversity, and island area could be attributed to greater habitat heterogeneity allowing the coexistence of species with different habitat requirements on larger islands (the habitat heterogeneity effect, Fig. 1c; [32, 33]). Alternatively, higher beta diversity within larger islands could simply arise from stronger dispersal limitation among localities that are spaced further apart (the dispersal limitation effect, Fig. 1c; [35]). By examining how both environmental and spatial factors influence alpha and beta diversity within islands, which has not been done before, this framework provides a useful approach for distinguishing ecological mechanisms generating island biogeographical patterns.

We applied this framework to study spatial patterns of soil bacterial and fungal diversity and test for their underlying mechanisms, using a cluster of 29 land-bridge islands in the Thousand Island Lake (TIL) in subtropical China as a model system. The 29 islands are of the same age, differ substantially in size (Fig. S1), and have experienced minimum levels of human disturbance since their formation, providing an excellent opportunity for exploring island biogeography questions. We collected a total of 306 soil samples from the 29 islands as well as the nearby mainland, and estimated soil bacterial and fungal composition and diversity via high-throughput sequencing. By simultaneously considering gamma, alpha, and beta diversity of soil bacteria and fungi within islands, as well as the relative importance of environmental and spatial factors for these diversity components, we aimed to unravel mechanisms underlying the biogeography of soil microbes on these islands. 


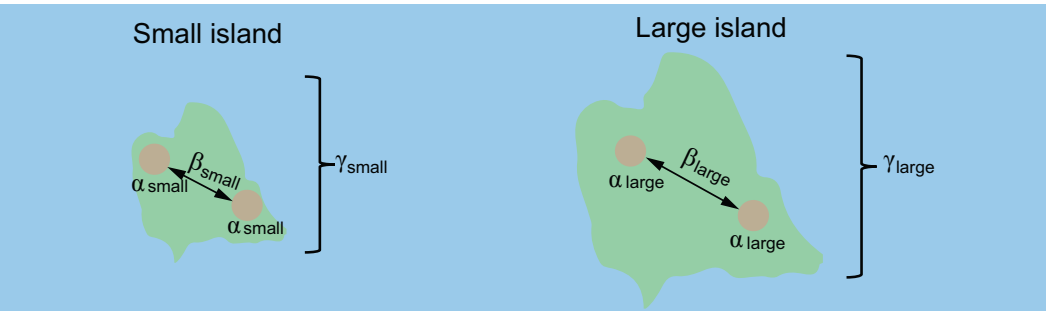

a Pure sampling effect
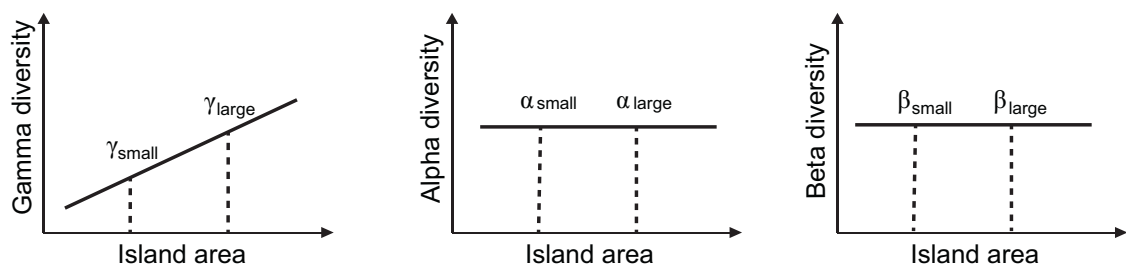

b Area per se or habitat quality
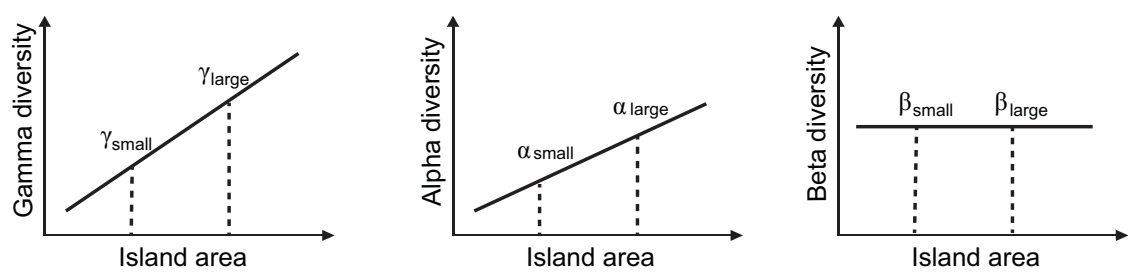

C Habitat heterogeneity or dispersal limitation
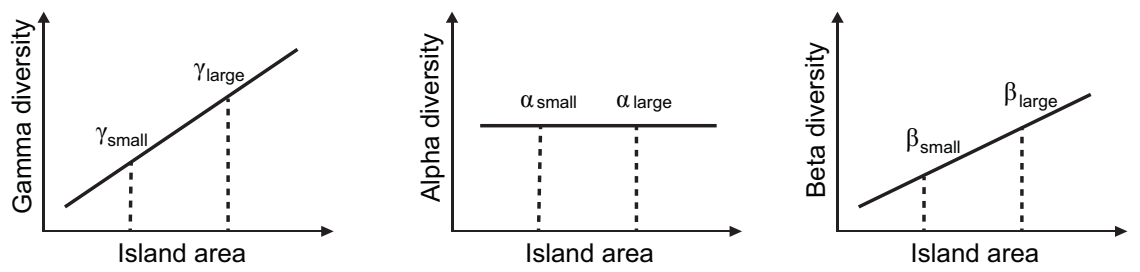

Fig. 1 A conceptual diagram illustrating the potential mechanisms behind the positive island species-area relationships, assuming that all islands share the same regional species pool. The total number of species on an island (gamma diversity) is decomposed to species richness within samples (alpha diversity) and sample-to-sample species turnover (beta diversity) within the island. a Gamma diversity, but not alpha or beta diversity, increases with island area. This pattern is in line with the prediction of the sampling effect, which posits that larger islands contain more individuals and thus accumulate more species by chance. b Gamma and alpha diversity, but not beta diversity, increase

\section{Methods}

\section{Study sites and sampling}

Our study was conducted in the Thousand Island Lake $\left(29^{\circ} 22^{\prime} \mathrm{N}\right.$ to $29^{\circ} 50^{\prime} \mathrm{N}$ and $118^{\circ} 34^{\prime} \mathrm{E}$ to $\left.119^{\circ} 15^{\prime} \mathrm{E}\right)$, a man-made reservoir created by damming in 1959, in subtropical China. The flooding inundated an area of $\sim 580 \mathrm{~km}^{2}$, transforming former hilltops in the area into islands. Islands are covered by secondary forests dominated by Pinus massoniana [36].

A cluster of 29 islands with minimum levels of human disturbance was selected as our study sites (Fig. S1). The with island area. This pattern is often considered as the evidence for the area per se effect, which emphasizes the importance of reduced local extinction risk on larger islands. Alternatively, we suggest that this pattern could also be explained by local habitat quality favoring more species on larger islands. c Gamma and beta diversity, but not alpha diversity, increase with island area. This pattern has often been explained by greater habitat heterogeneity on larger islands. Alternatively, we suggest that this pattern could also arise from stronger dispersal limitation on larger islands.

size of the 29 islands varies from 0.08 to $1153.87 \mathrm{ha}$. We used a hierarchical sampling regime to collect soil samples. On each island, we established one to six permanently marked $20 \times 20 \mathrm{~m}^{2}$ plots (two $10 \times 10 \mathrm{~m}^{2}$ quadrats on the smallest island), with the number of plots roughly proportional to island area on the logarithmic $\left(\log _{10}\right)$ scale [32]. Each plot was further divided into four $10 \times 10 \mathrm{~m}^{2}$ quadrats. In addition, we set up one $10,000 \mathrm{~m}^{2}$ control plot on the adjacent mainland, with 20 quadrats $\left(10 \times 10 \mathrm{~m}^{2}\right)$ evenly distributed within the plot. For each quadrat on the islands and mainland, four evenly distributed soil cores $(3 \mathrm{~cm}$ diameter to $10 \mathrm{~cm}$ depth) were taken and 
mixed to form one composite sample, resulting in a total of 306 soil samples.

Sampling was carried out in mid-May 2015. Samples were placed in sterile plastic bags, sealed and placed on ice, and immediately transported to the laboratory. All soil samples were carefully homogenized prior to further treatment. For each sample, a $\sim 2 \mathrm{~g}$ subsample was placed into a sterilized tube at $-80^{\circ} \mathrm{C}$ before DNA extraction. A second subset of fresh soil was used for soil moisture measurement, and a third subset of air-dried soil was preserved for subsequent soil chemistry analysis.

\section{Microbial analyses}

Soil DNA was extracted by the MoBio PowerSoil DNA extraction kit (MO BIO Laboratories, Carlsbad, CA, USA). For bacteria, we targeted the V4 region of the $16 \mathrm{~S}$ ribosomal RNA (rRNA) gene, using 515-F (GTGCCAGCM GCCGCGGTAA) and 806-R (GGACTACHVGGGTWT CTAAT) primer pairs [37]. For fungi, we targeted the second nuclear ribosomal internal transcribed spacer (ITS2) region of the rRNA operon, using the ITS3 (GCATCGA TGAAGAACGCAGC) and ITS4 (TCCTCCGCTTA TTGATATGC) primer pairs [38]. To permit multiplexing of samples, a 12-bp barcode unique to each sample was added to the reverse primers during primer synthesis. PCR amplification was performed in triplicate for both the $16 \mathrm{~S}$ rRNA gene and the ITS2 region with $20 \mu \mathrm{l}$ reactions containing $10 \mu \mathrm{l} 2 \times$ premix (TaKaRa Bio, Mountain view, CA, USA), $0.4 \mu \mathrm{l}$ of both forward and reversed primers (10 mM), and $10 \mathrm{ng}$ template DNA. The PCR program for $16 \mathrm{~s}$ rRNA gene was as follows: preheat $1 \mathrm{~min}$ at $94{ }^{\circ} \mathrm{C}$, then 30 cycles of $94^{\circ} \mathrm{C}$ for $10 \mathrm{~s}, 53{ }^{\circ} \mathrm{C}$ for $25 \mathrm{~s}, 68^{\circ} \mathrm{C}$ for $45 \mathrm{~s}$, and a final extension at $68^{\circ} \mathrm{C}$ for $8 \mathrm{~min}$. As for ITS2 region, the PCR program was as follows: preheat $15 \mathrm{~min}$ at $95^{\circ} \mathrm{C}$, then 30 cycles at $95^{\circ} \mathrm{C}$ for $10 \mathrm{~s}, 55^{\circ} \mathrm{C}$ for $30 \mathrm{~s}, 72^{\circ} \mathrm{C}$ for $1 \mathrm{~min}$, and a final extension at $72^{\circ} \mathrm{C}$ for $10 \mathrm{~min}$. Negative controls were included in each batch of DNA extraction and PCR. PCR products from all samples were pooled together in equimolar concentrations, and purified by using the E.Z.N.A. ${ }^{\circledR}$ Gel Extraction Kit (Omega Bio-tek, Norcross, GA, USA). The pooled PCR products were subsequently sequenced on a $2 \times 300 \mathrm{bp}$ paired-end Illumina MiSeq platform (Illumina; San Diego, CA, USA) at Sun Yat-sen University (Guangzhou, China).

The raw sequence data were processed with the Mothur software package [39] for quality filtering and assembling of pair-end reads. Strict quality control steps were applied to the sequencing data. First, assembled contigs without exact match to one of the barcode sets or primers (degenerate bases were not taken into consideration) were discarded. Subsequently, the remaining sequences were clustered into operational taxonomic units (OTUs) based on a $97 \%$ similarity threshold with the UPARSE algorithm [40], using the "-cluster_otus" command in USEARCH, with chimera sequences identified and eliminated during the procedure. Sequences found only once across all samples were treated as singletons and removed from subsequent analyses. Taxonomic classification of each OTU of bacteria and fungi was determined using the Ribosomal Database Project (RDP) classifier [41] with a confidence threshold of 0.8 (bacteria) and 0.5 (fungi) against the SILVA [42] and the UNITE [43] database, respectively. OTUs that were not classified into bacteria or fungi were removed. The samples were rarefied to an even number of sequences per sample (8381 and 2720 for bacteria and fungi, respectively).

\section{Soil properties}

We measured nine soil chemical properties that could potentially influence microbial communities (Table S1). Soil moisture was measured by oven drying $10 \mathrm{~g}$ of fresh soil at $105^{\circ} \mathrm{C}$ until constant weight. Soil $\mathrm{pH}$ was measured in soil suspension with a 1:2.5 ratio of soil to deionized water. Soil total organic carbon (TOC) was measured by the potassium dichromate oxidation method following the modified Walkley-Black procedure, and total $\mathrm{N}$ was measured by the semimicro-Kjeldahl method (Kjeltec 2200 Auto Distillation Unit, FOSS, Hillerød, Sweden). Soil total P and available $\mathrm{P}$ were measured by the colorimetric method using a UV-Visible Spectrophotometer (UV-2550, Shimadzu, Kyoto, Japan). Soil available $\mathrm{Ca}, \mathrm{Mg}$, and $\mathrm{Al}$ were extracted by the Mehlich-III solution and measured using Inductively Coupled Plasma Optical Emission Spectrometry (Optima 2100 DV, Perkin-Elmer, Waltham, MA, USA). Prior to analysis, data on these soil properties were standardized to have a mean value of 0 and variance of 1 .

\section{Statistical analyses}

We assessed three components of bacterial and fungal diversity for each island: gamma, alpha, and beta diversity. Gamma diversity, which was defined as the estimated total richness of the whole island, was calculated as the Chao2 estimator based on OTUs' incidence frequencies on each island [44]. Alpha diversity was defined as the average OTU richness per sample within an island. Beta diversity was defined as the average Bray-Curtis dissimilarity values among samples within the island, and visualized via nonmetric multidimensional scaling (NMDS). We also calculated other diversity indices for gamma (i.e., Chao1, ACE, ICE, Jack1, Jack2), alpha (i.e., the exponential of Shannon entropy, the inverse Simpson index), and beta (i.e., Jaccard index, Sorenson index, the Bray-Curtis based Raup-Crick index, and measures based on Hill numbers) diversity $[45,46]$. They all yielded similar results (Tables S2, S3). 
Further, to assess the potential influences of the sampling effect, gamma diversity was also calculated as the total OTU richness rarefied to an equal number of reads, or an equal number of samples, per island. We also calculated the rarefaction curve of each island with gamma diversity as a function of the sample size for each island. To compare within-island beta diversity across samples of similar spatial distances, we calculated the average beta diversity among samples within the $20 \mathrm{~m} \times 20 \mathrm{~m}$ plots for each island. Island isolation was measured as the distance to the nearest island (DNI) or nearest distance to the mainland (NDM). We used linear and segmented regressions to assess the effects of island area and isolation on the mean alpha, beta and gamma diversity of soil bacteria and fungi on each island. Where appropriate, data were $\log$ transformed to improve model fit and improve the homoscedasticity of residuals.

We used multiple linear regressions and multiple regressions on distance matrices [47] to assess the importance of spatial and individual environmental factors on alpha and beta diversity, respectively. For alpha diversity, the nine soil properties of each soil sample were considered as independent variables. For beta diversity, we considered spatial distance among samples, and the dissimilarity in soil properties (based on Euclidean distances) within island as independent variables. The importance of the variables, as well as the variance explained by the models, were estimated using the lmg function in the R package relaimpo [48]. We then used variation partitioning to distinguish the contribution of spatial and environmental factors to beta diversity, where spatial distance and environmental dissimilarity among samples within island were used as predictor variables. Variable selection was implemented by using full subset model selection and by minimizing the Akaike Information Criterion (AIC), which alleviates variable collinearity [49]. Variation partitioning was performed with the varpart function in the $\mathrm{R}$ package vegan [50].

We further used structural equation modeling (SEM) to disentangle the causal pathways through which island spatial and environmental factors influence alpha, beta, and gamma diversity of soil bacteria and fungi. We constructed the same a priori model for soil bacteria and fungi, considering all possible mechanisms whereby island and soil characteristics influence microbial diversity, including the sampling effect represented by a direct link between island area and gamma diversity (i.e., island area influences gamma diversity without changing alpha and beta diversity; Fig. 1a). Habitat heterogeneity of each island was calculated as the average pairwise Euclidean distances among samples, based on the nine soil properties. We simplified the initial models by eliminating nonsignificant pathways before we attained the final models. Model adequacy was determined using the $\chi^{2}$ test and AIC. Structural equation modeling was conducted with the $\mathrm{R}$ package sem [51]. We performed all statistical analyses in $\mathrm{R}$ version 3.3.2 [52].

\section{Results}

A total of 9,022,457 and 4,535,687 high-quality sequences were obtained for soil bacteria and fungi across all samples, respectively, with an average of 29,485 $\pm 10,109$ (bacteria, mean $\pm \mathrm{SD}$ ) and 14,822 \pm 9553 (fungi, mean $\pm \mathrm{SD}$ ) sequences detected per sample. After clustering sequences at the $97 \%$ similarity level and removing singletons, we obtained 20,078 and 10,579 operational taxonomic units (OTUs) for bacteria and fungi, respectively. After rarefying all samples to the same number of sequences (8381 for bacteria, 2720 for fungi), an average of $1434 \pm 177$ bacterial OTUs and $337 \pm 52$ fungal OTUs were detected per sample. On average, 4718 bacterial OTUs and 1287 fungal OTUs were detected per island, with the range being 1750-7788 for bacteria and 463 to 2229 for fungi. At the phylum level, soil bacterial communities were dominated by Proteobacteria (20.9-29.8\%), Acidobacteria (16.1-30.6\%), Verrucomicrobia (8.7-28.9\%), and Chloroflexi (6.6-21.2\%) across all islands (Fig. S2a). For fungal communities, Ascomycota $(29.2-66.6 \%)$ and Basidiomycota (16.7-46.9\%) were the dominant phyla (Fig. S2b), with Russulaceae (1.4-20.6\%), Mortierellaceae (1.7-17.2\%), Umbelopsidaceae (1.5-19.4\%), and Trimorphomycetaceae (1.1-14.1\%) being the dominant families.

Both linear and segmented regressions showed that bacterial and fungal diversity at the island scale (gamma diversity) increased significantly with island area (Fig. 2a, b and Fig. S3). The gamma diversity-area relationships were less positive but remained statistically significant after we controlled for the variation in the total number of sequences (Fig. S4), or the total number of samples (Fig. S5), across islands, suggesting that the sampling effect played an important, but non-exclusive, role in driving the observed relationships. In addition, all islands shared similar-shaped rarefaction curves for gamma diversity, with larger islands generally showing greater gamma diversity at equal sample size (Fig. S6). The nearby mainland exhibited greater bacterial and fungal gamma diversity than all but the largest islands (Fig. 2a, b). Island isolation, measured as either DNI or NDM, did not affect bacterial or fungal gamma diversity (Fig. S7, Table S3). These relationships were robust to the use of different richness estimators (Table S3).

Soil bacteria and fungi, however, exhibited markedly different diversity patterns within islands. Bacterial alpha diversity, measured as the average OTU richness per sample within an island, increased with island area, whereas fungal alpha diversity was unaffected by island area (Fig. 2c, d). By contrast, bacterial beta diversity, measured as the average Bray-Curtis dissimilarity among samples within an 
Fig. 2 The effects of island area on the gamma, alpha and beta diversity of soil bacteria and fungi. Panels a, c, e are for bacterial gamma, alpha and beta diversity, respectively; panels $\mathbf{b}$, $\mathbf{d}, \mathbf{f}$ are for fungal gamma, alpha and beta diversity, respectively. Gamma diversity was measured as the estimated total OTU richness (based on Chao2 estimator) per island. Alpha diversity was measured as the average OTU richness per sample within each island. Beta diversity was measured as average pairwise Bray-Curtis dissimilarities among samples within each island. Error bars represent standard error. The solid lines represent significant linear regressions $(P<0.05)$ and the dashed lines represent marginally significant regressions $(P<0.10)$. ML indicates data from the mainland.

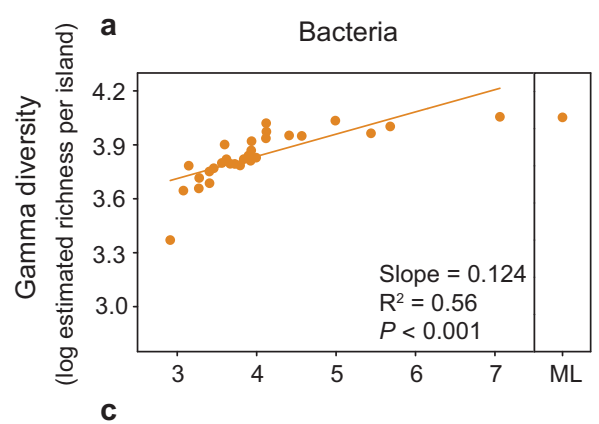

b
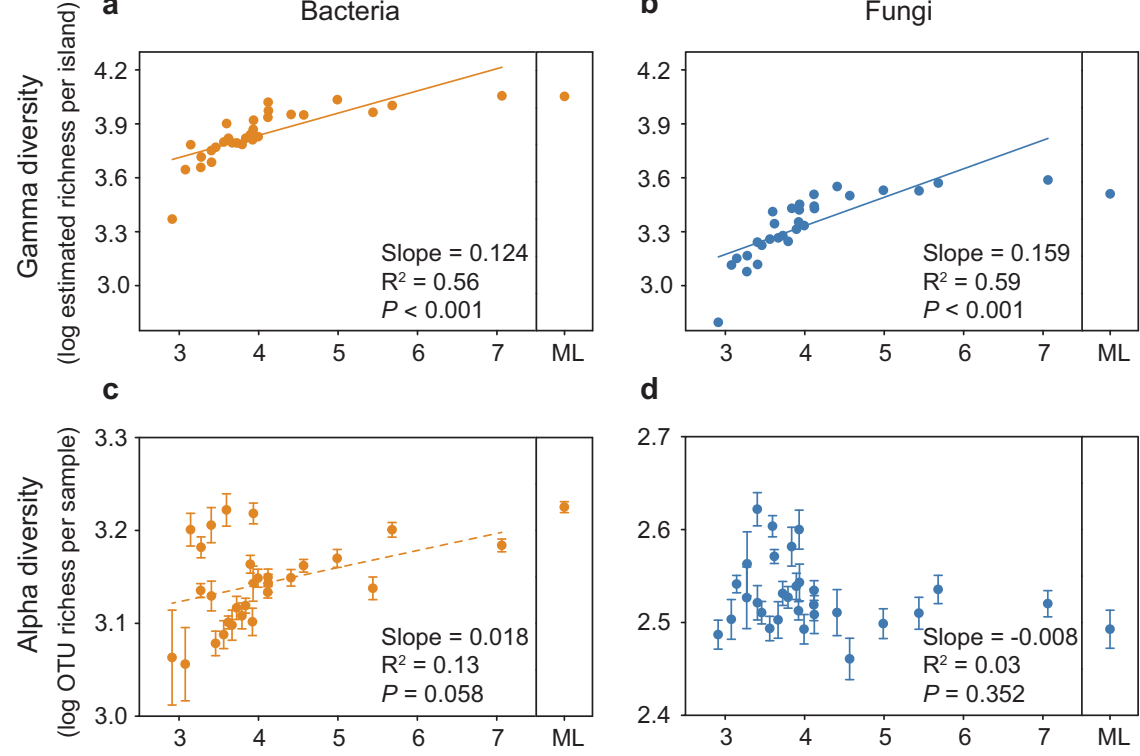

d

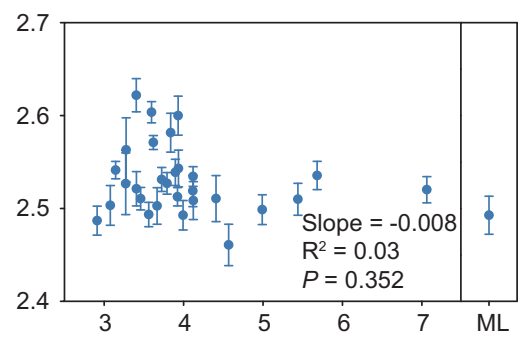

f

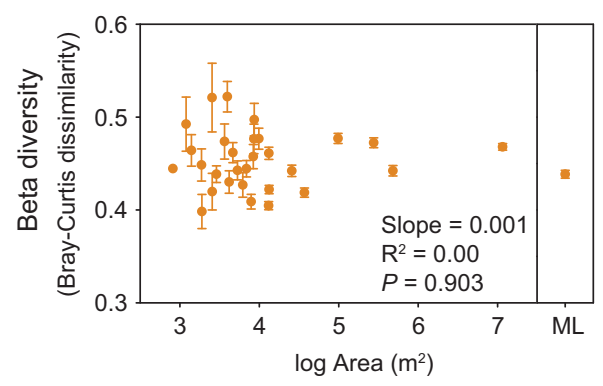

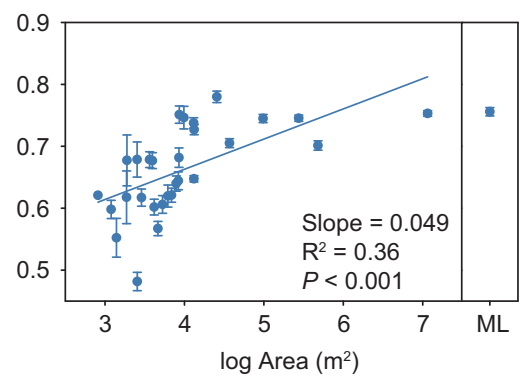

island, was not related to island area, whereas fungal beta diversity significantly increased with area (Fig. 2e, f and Fig. S8). Qualitatively similar results were obtained when only considering beta diversity among samples within the $20 \mathrm{~m} \times 20 \mathrm{~m}$ plot (Fig. S9). These results suggest that the assembly of bacterial and fungal communities was likely driven by different mechanisms. Neither bacterial nor fungal within-island (alpha and beta) diversity was affected by island isolation (Fig. S7, Table S3).

We tested the roles of environmental filtering and spatial processes on soil microbial assembly on the TIL islands, by comparing the variation in within-island alpha and beta diversity explained by environmental and spatial variables. We found that soil moisture, as well as the habitat heterogeneity of all soil properties, significantly increased with island area (Table S4). All other soil properties were not related to island area (Table S4). Multiple regression showed that soil properties accounted for a sizable fraction $(\sim 35 \%)$ of the variation in bacterial alpha diversity. Soil moisture was identified as the most important predictor of bacterial alpha diversity, explaining more than $12 \%$ of the variation alone (Fig. 3a). In contrast, soil properties accounted for much less variation in fungal alpha diversity. Soil available $\mathrm{Ca}$, the best explanatory variable, explained $<6 \%$ of the variation in fungal alpha diversity; each of the other soil properties accounted for less than 2\% (Fig. 3a). Multiple regressions on distance matrices showed that while a small yet significant portion $(\sim 11 \%)$ of the variation in bacterial beta diversity can be explained by the dissimilarities in soil properties among samples, virtually none can be explained by spatial distance among samples (Fig. 3b). In contrast, spatial distances among samples were a substantially better predictor of fungal beta diversity than soil properties (Fig. 3b). These results were further confirmed by variation partitioning of beta diversity into environmental and spatial components, which showed that environmental and spatial variables explained a substantially larger fraction of variation in bacterial and fungal beta diversity, respectively (Fig. 3c, d).

We further used SEM to link microbial assembly mechanisms to island-scale species-area relationships. SEM revealed that besides the direct link between island area and gamma diversity, which is indicative of the sampling effect, greater bacterial and fungal gamma diversity on larger islands were associated with greater alpha diversity within 
Fig. 3 The fraction of the variation in alpha and beta diversity of soil bacteria and fungi explained by

environmental and spatial predictors. The importance of individual predictor variables was assessed using multiple linear regression models of alpha (a) and beta (b) diversity, and the relative importance of soil environment variables (ENV) and spatial distance (SPAT) among samples within island was assessed using variation partitioning of bacterial (c) and fungal (d) beta diversity. a

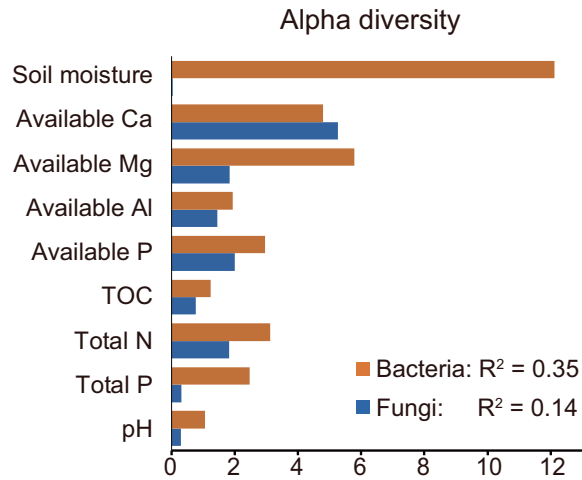

b

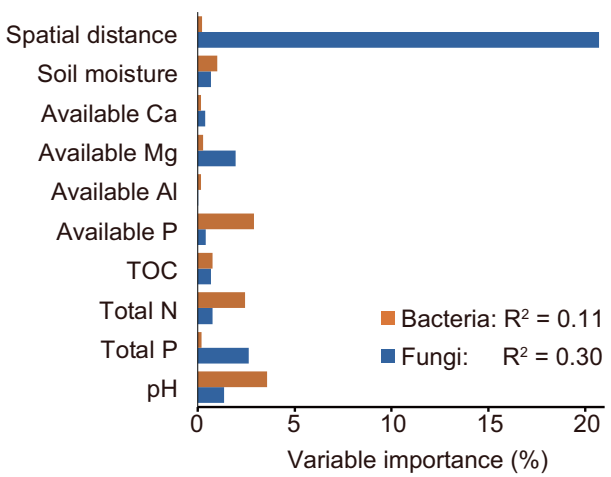

C

Beta diversity of bacteria

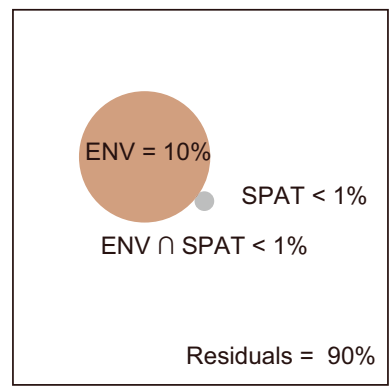

d

Beta diversity of fungi

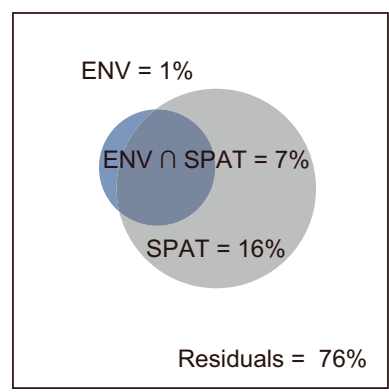

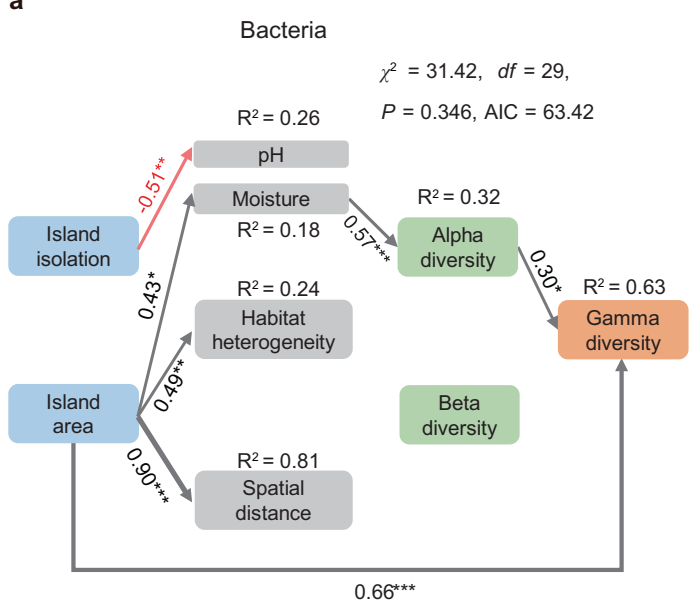

Fig. 4 Structural equation models considering the direct and indirect pathways via which island area and isolation influence alpha, beta, and gamma diversity of soil bacteria and fungi. Panel $\mathbf{a}$ is for bacteria; panel $\mathbf{b}$ is for fungi. Island isolation was measured as distance to the nearest island (note that using the nearest distance to the

samples and greater beta diversity between samples, respectively (Fig. 4a, b). For bacteria, the greater alpha diversity on larger islands was driven by higher soil moisture on those islands; habitat heterogeneity, which was higher on larger islands, as well as spatial distance among samples, had little effect on bacterial alpha or beta diversity (Fig. 4a). For fungi, the greater beta diversity on larger islands was mainly driven by the increased spatial distance

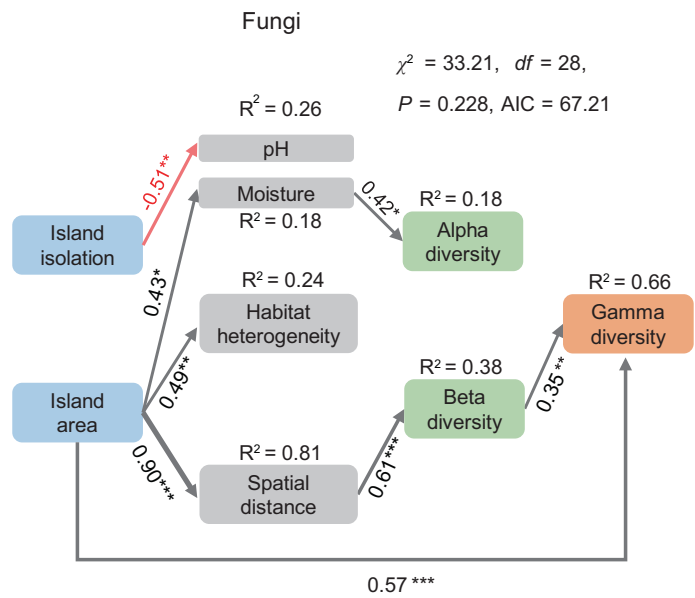

mainland yielded similar results). Black and red arrows indicate significant positive and negative pathways, respectively $\left({ }^{*} P<0.05\right.$, $* * P<0.01, * * * P<0.001)$. Numbers along the arrows indicate standardized path coefficients. $R^{2}$ represents the proportion of variance explained for the dependent variable.

among samples; habitat heterogeneity also did not affect fungal beta diversity (Fig. 4b).

\section{Discussion}

Our study provides, to our knowledge, the first empirical evidence that soil bacteria and fungi on islands exhibited 
similar island-scale biogeographic patterns, but that these similar patterns were driven by strikingly different mechanisms. For soil bacteria, the loss of island-scale diversity on smaller islands was mainly caused by the decline of within-sample (alpha) diversity within island. At first glance, this pattern appears to be in line with the prediction of the area per se effect (see Fig. 1b), which suggests that higher alpha diversity on larger islands can be driven by a neutral equilibrium between species immigration and extinction, as postulated by the theory of island biogeography [4]. However, we found that island area influenced alpha diversity mainly through altering soil properties, particularly soil moisture (Figs. 3 and 4), pointing to the importance of variation in habitat quality among islands for driving the observed bacterial speciesarea relationship (Fig. 1b). This aspect of our findings is thus consistent with previous work showing that bacteria tend to be more responsive than fungi to water stress [53-55]. In our study, smaller islands are characterized by lower vegetation density, as well as by increased edge effects associated with their greater island perimeter to area ratio [36], which may have led to increased insolation, wind exposure and evapotranspiration, and, in turn, lower soil moisture. Overall, our results illustrate habitat quality as an important determinant of soil bacterial diversity. Likewise, several other studies have found that environmental variables better predict soil bacterial community structure than spatial distance across various spatial scales (e.g., $[12,56,57])$.

Unlike bacteria, the positive island species-area relationship for fungi was primarily driven by increased beta diversity among localities on larger islands (Fig. 4b). The increased beta diversity has typically been interpreted as evidence for greater habitat heterogeneity on larger islands $[28,32,58]$. Neutral theory, however, suggests that the same pattern could arise from dispersal limitation [35, 59], without incurring differences in species or environmental characteristics. In our study, although the heterogeneity of soil properties increased on larger islands, habitat heterogeneity was not a significant predictor of fungal beta diversity within islands. Instead, spatial distance between samples strongly influenced fungal within-island beta diversity. These results thus point to the importance of dispersal limitation in shaping fungal community assembly within islands, and, in turn, the observed fungal species-area relationship (Fig. 1c). Note that under dispersal limitation, the presence of a tradeoff between species dispersal and competitive ability may also contribute to increased fungal beta and gamma diversity for larger islands [60], a mechanism that cannot be evaluated with our current data. Fungal communities are known to be more influenced by dispersal limitation than bacteria [61, 62]. Recent research has shown that the majority of fungal spores disperse over short distances (from centimeters to meters; [63]), and that dispersal limitation can operate to influence fungal com-

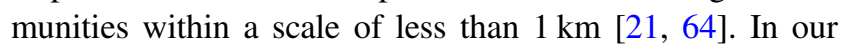
study system, although aeolian processes may transport spores of various fungal species among islands, with island isolation seemingly posing little barrier for dispersal (see next paragraph), the presence of forest canopy on islands may lower wind velocity and reduce the dispersal of fungal spores within island [65]. Such dispersal limitation is likely stronger on larger islands, which support more dense forest canopy [66]. In line with this prediction, we found that fungal beta diversity among samples within a $20 \mathrm{~m} \times 20 \mathrm{~m}$ plot also significantly increased with island area, even though these samples share similar spatial distances across all islands (Fig. S9). In contrast, island area and spatial distance were poor predictors of bacterial beta diversity within islands and plots (Figs. 3 and 4, and Fig. S9).

It is notable that for both bacteria and fungi, their islandlevel (gamma) diversity was not affected by island isolation, a pattern at odds with the theory of island biogeography predicting that more isolated islands should contain fewer species [4]. Similar non-significant species-isolation relationships have also been found for higher organisms (e.g., plants, birds, lizards, small mammals) inhabiting the TIL islands [36, 66, 67]. Together, these results suggest that the spatial discreteness of the TIL islands did not result in across-island dispersal limitation for a variety of organisms, probably due to the relatively recent isolation history ( 60 years) of these islands and their close proximity to the mainland $(<4 \mathrm{~km})$.

Several limitations of our study are worth noting. First, DNA markers used for bacteria and fungi (i.e., $16 \mathrm{~S}$ for bacteria and ITS2 for fungi) are known to have different taxonomic resolutions [68]. It is therefore possible that bacterial communities may exhibit finer spatial structure that cannot be detected with current methods, and that fungal communities may exhibit environmental signatures that are visible only at coarser taxonomic levels [69]. Future studies should explore these possibilities. Second, given the presence of a large number of rare microbial species and the difficulty of capturing them during sampling and sequencing, the accuracy of estimated microbial diversity values may be questioned. The consistency of our results based on different diversity metrics eases this concern (Tables S2, S3), although the robustness of these metrics in the context of evaluating species-area mechanisms still needs to be investigated further. Third, despite the measurement of common soil environmental variables, it is worth noting that other unmeasured variables could also influence microbial communities. It is possible that these unmeasured variables, including plant community structure and historical factors (e.g., past dispersal events, past environmental conditions), could be spatially structured and influence microbial 
communities through the apparent effect of spatial distance [70]. Therefore, we cannot completely exclude the role of habitat heterogeneity in contributing to fungal species-area relationships. Nevertheless, analyses of our microbial data using null models, without considering soil environmental variables, also indicate that dispersal limitation dominated the assembly of soil fungal communities within the TIL islands (see [71]).

While studies of habitat loss and fragmentation in the Thousand-Island Lake and elsewhere have traditionally focused on their effects on higher organisms [36, 72, 73], our study revealed that both bacterial and fungal diversity declined on smaller islands, providing direct empirical evidence that habitat loss and fragmentation are also threatening the diversity of microorganisms. Our study further reveals that the loss of bacterial and fungal diversity on smaller islands is driven by contrasting mechanisms. Poorer habitat quality on smaller islands drives the systematic decline of diversity within samples for bacteria, whereas reduced dispersal limitation on smaller islands causes lower diversity among samples for fungi. These contrasting assembly mechanisms defy a universal explanation for the similar island biogeographic patterns observed for bacteria and fungi, with important implications for the conservation of bacterial and fungal diversity. In particular, the different mechanisms suggest that preventing habitat degradation would be an effective strategy for reducing the extinction risk of soil bacteria, whereas maintaining large habitat fragments would be more effective for the conservation of soil fungal diversity. The generality of our results, however, would need to be assessed for other island systems.

\section{Data availability}

DNA sequence data are accessible at the NCBI-SRA under the accession number PRJNA517449. All other data that support the findings of this study can be accessed via the Dryad Digital Repository (https://doi.org/10.5061/dryad. gqnk98sj8).

Acknowledgements We thank Marc Cadotte, Tadashi Fukami, Mark Hay, Fangliang He and Peter Morin for constructive comments. This project was financially supported by the National Science Foundation of USA (DEB-1342754, DEB-1342757, DEB-1856318, and CBET-1833988) and National Natural Science Foundation of China (NSFC31361123001, NSFC31971553, and NSFC 31700452). SPL was partly supported by a British Ecological Society Research Grant (BES SR16/1296).

Author contributions LJ, WSS, and SPL conceived the study. SPL, $\mathrm{PW}, \mathrm{XY}$, and CM performed the study. SPL, PW, YC, and MCW performed data analyses. SPL and LJ wrote the paper with input from all authors.

\section{Compliance with ethical standards}

Conflict of interest The authors declare that they have no conflict of interest.

Publisher's note Springer Nature remains neutral with regard to jurisdictional claims in published maps and institutional affiliations.

Open Access This article is licensed under a Creative Commons Attribution 4.0 International License, which permits use, sharing, adaptation, distribution and reproduction in any medium or format, as long as you give appropriate credit to the original author(s) and the source, provide a link to the Creative Commons license, and indicate if changes were made. The images or other third party material in this article are included in the article's Creative Commons license, unless indicated otherwise in a credit line to the material. If material is not included in the article's Creative Commons license and your intended use is not permitted by statutory regulation or exceeds the permitted use, you will need to obtain permission directly from the copyright holder. To view a copy of this license, visit http://creativecommons. org/licenses/by/4.0/.

\section{References}

1. Losos JB, Ricklefs RE. Adaptation and diversification on islands. Nature. 2009;457:830-6.

2. Wallace AR. On the zoological geography of the Malay archipelago. J Proc Linn Soc. 1860;4:172-84.

3. Whittaker RJ, Fernández-Palacios JM, Matthews TJ, Borregaard MK, Triantis KA. Island biogeography: taking the long view of nature's laboratories. Science. 2017;357:eaam8326.

4. MacArthur RH, Wilson EO. The theory of island biogeography. Princeton, New Jersey: Princeton University Press; 1967.

5. Helmus MR, Mahler DL, Losos JB. Island biogeography of the anthropocene. Nature. 2014;513:543-6.

6. Losos, JB, Ricklefs, RE. The theory of island biogeography revisited princeton. New Jersey: Princeton University Press; 2010.

7. Simberloff D. Experimental zoogeography of islands: effects of island size. Ecology. 1976;57:629-48.

8. Triantis KA, Guilhaumon F, Whittaker RJ. The island species-area relationship: biology and statistics. J Biogeogr. 2012;39:215-31.

9. Delgado-Baquerizo M, Oliverio AM, Brewer TE, BenaventGonzalez A, Eldridge DJ, Bardgett RD, et al. A global atlas of the dominant bacteria found in soil. Science. 2018;359:320-5.

10. Fierer N, Jackson RB. The diversity and biogeography of soil bacterial communities. Proc Natl Acad Sci USA. 2006;103: 626-31.

11. Hanson CA, Fuhrman JA, Horner-Devine MC, Martiny JBH. Beyond biogeographic patterns: processes shaping the microbial landscape. Nat Rev Microbiol. 2012;10:497-506.

12. Bahram M, Hildebrand F, Forslund SK, Anderson JL, Soudzilovskaia NA, Bodegom PM, et al. Structure and function of the global topsoil microbiome. Nature. 2018;560:233-7.

13. Martiny JBH, Bohannan BJ, Brown JH, Colwell RK, Fuhrman JA, Green JL, et al. Microbial biogeography: putting microorganisms on the map. Nat Rev Microbiol. 2006;4:102-12.

14. Tedersoo L, Bahram M, Polme S, Koljalg U, Yorou NS, Wijesundera R, et al. Global diversity and geography of soil fungi. Science. 2014;346:1256688.

15. Davison J, Moora M, Öpik M, Ainsaar L, Ducousso M, Hiiesalu I, et al. Microbial island biogeography: isolation shapes the life history characteristics but not diversity of root-symbiotic fungal communities. ISME J. 2018;12:2211-24. 
16. Green JL, Holmes AJ, Westoby M, Oliver I, Briscoe D, Dangerfield $\mathrm{M}$, et al. Spatial scaling of microbial eukaryote diversity. Nature. 2004;432:747-50.

17. Horner-Devine MC, Lage M, Hughes JB, Bohannan BJM. A taxaarea relationship for bacteria. Nature. 2004;432:750-3.

18. Power JF, Carere CR, Lee CK, Wakerley GLJ, Evans DW, Button $\mathrm{M}$, et al. Microbial biogeography of 925 geothermal springs in New Zealand. Nat Commun. 2018;9:2876.

19. Bell T, Ager D, Song J-I, Newman JA, Thompson IP, Lilley $\mathrm{AK}$, et al. Larger islands house more bacterial taxa. Science. 2005;308:1884.

20. Peay KG, Bruns TD, Kennedy PG, Bergemann SE, Garbelotto M. A strong species-area relationship for eukaryotic soil microbes: island size matters for ectomycorrhizal fungi. Ecol Lett. 2007;10:470-80.

21. Peay KG, Garbelotto M, Bruns TD. Evidence of dispersal limitation in soil microorganisms: isolation reduces species richness on mycorrhizal tree islands. Ecology. 2010;91:3631-40.

22. Belisle M, Peay KG, Fukami T. Flowers as islands: spatial distribution of nectar-inhabiting microfungi among plants of Mimulus aurantiacus, a hummingbird-pollinated shrub. Microb Ecol. 2012;63:711-8.

23. Teittinen A, Soininen J. Testing the theory of island biogeography for microorganisms patterns for spring diatoms. Aquat Microb Ecol. 2015;75:239-50.

24. Mendenhall CD, Karp DS, Meyer CF, Hadly EA, Daily GC. Predicting biodiversity change and averting collapse in agricultural landscapes. Nature. 2014;509:213-7.

25. Stuart YE, Losos JB, Algar AC. The island-mainland species turnover relationship. Proc R Soc B. 2012;279:4071-7.

26. Itescu Y. Are island-like systems biologically similar to islands? A review of the evidence. Ecography. 2019;42:1298-314.

27. Matthews TJ, Guilhaumon F, Triantis KA, Borregaard MK, Whittaker RJ. On the form of species-area relationships in habitat islands and true islands. Glob Ecol Biogeog. 2016;25:847-58.

28. Connor EF, McCoy ED. The statistics and biology of the speciesarea relationship. Am Nat. 1979;113:791-833.

29. Williams, CB. Patterns in the balance of nature. New York: Academic Press; 1964.

30. Ewers RM, Didham RK. Confounding factors in the detection of species responses to habitat fragmentation. Biol Rev. 2006;81: 117-42.

31. Phillips HR, Halley JM, Urbina-Cardona JN, Purvis A. The effect of fragment area on site-level biodiversity. Ecography. 2018;41:1220-31.

32. Schoereder JH, Galbiati C, Ribas CR, Sobrinho TG, Sperber CF, DeSouza O, et al. Should we use proportional sampling for speciesarea studies? J Biogeogr. 2004;31:1219-26.

33. Stevens GC. Dissection of the species-area relationship among wood-boring insects and their host plants. Am Nat. 1986;128:35-46.

34. Schrader J, Moeljono S, Keppel G, Kreft H. Plants on small islands revisited: the effects of spatial scale and habitat quality on the species-area relationship. Ecography. 2019;42:1405-14.

35. Shen G, Yu M, Hu XS, Mi X, Ren H, Sun IF, et al. Species-area relationships explained by the joint effects of dispersal limitation and habitat heterogeneity. Ecology. 2009;90:3033-41.

36. Hu G, Feeley KJ, Wu J, Xu G, Yu M. Determinants of plant species richness and patterns of nestedness in fragmented landscapes: evidence from land-bridge islands. Landsc Ecol. 2011;26:1405-17.

37. Caporaso JG, Lauber CL, Walters WA, Berg-Lyons D, Lozupone CA, Turnbaugh PJ, et al. Global patterns of $16 \mathrm{~S}$ rRNA diversity at a depth of millions of sequences per sample. Proc Natl Acad Sci USA. 2011;108:4516-22.

38. White TJ, Bruns T, Lee S, Taylor JW. Amplification and direct sequencing of fungal ribosomal RNA genes for phylogenetics. In: PCR protocols: a guide to methods and applications. New York, NY: Academic Press, Inc.; 1990. p. 315-22.
39. Schloss PD. A high-throughput DNA sequence aligner for microbial ecology studies. PLoS ONE. 2009;4:e8230.

40. Edgar RC. UPARSE: highly accurate OTU sequences from microbial amplicon reads. Nat Methods. 2013;10:996-8.

41. Wang Q, Garrity GM, Tiedje JM, Cole JR. Naive Bayesian classifier for rapid assignment of rRNA sequences into the new bacterial taxonomy. Appl Environ Microbiol. 2007;73:5261-7.

42. Quast C, Pruesse E, Yilmaz P, Gerken J, Schweer T, Yarza P, et al. The SILVA ribosomal RNA gene database project: improved data processing and web-based tools. Nucl Acids Res. 2013;41:D590-6.

43. Abarenkov K, Henrik Nilsson R, Larsson KH, Alexander IJ, Eberhardt U, Erland S, et al. The UNITE database for molecular identification of fungi-recent updates and future perspectives. $\mathrm{N}$ Phytol. 2010;186:281-5.

44. Chao A. Nonparametric estimation of the number of classes in a population. Scand J Stat. 1984;11:265-70.

45. Stegen JC, Lin XJ, Fredrickson JK, Konopka AE. Estimating and mapping ecological processes influencing microbial community assembly. Front Microbiol. 2015;6:370.

46. Chao A, Chiu CH, Jost L. Unifying species diversity, phylogenetic diversity, functional diversity and related similarity and differentiation measures through Hill numbers. Annu Rev Ecol, Evol, Syst. 2014;45:297-324.

47. Lichstein JW. Multiple regression on distance matrices: a multivariate spatial analysis tool. Plant Ecol. 2007;188:117-13.

48. Gröemping U. Relative importance for linear regression in R: the package relaimpo. J Stat Softw. 2006;17:1-27.

49. Fisher R, Wilson SK, Sin TM, Lee AC, Langlois TJ. A simple function for full-subsets multiple regression in ecology with $\mathrm{R}$. Ecol Evol. 2018;8:6104-13.

50. Oksanen J, Guillaume Blanchet F, Friendly M, Kindt R, Legendre $\mathrm{P}$, et al. Vegan: community ecology package. $\mathrm{R}$ package version 2.5-1. https://CRAN.R-project.org/package=vegan (2018).

51. Fox J. Structural equation modeling with the sem package in R. Struct Equ Model. 2006;13:465-86.

52. R Core Team. R: a language and environment for statistical computing. Vienna, Austria: R Foundation for Statistical Computing, Vienna, Austria; 2018.

53. de Vries FT, Griffiths RI, Bailey M, Craig H, Girlanda M, Gweon HS, et al. Soil bacterial networks are less stable under drought than fungal networks. Nat Commun. 2018;9:3033.

54. Manzoni S, Schimel JP, Porporato A. Responses of soil microbial communities to water stress: results from a meta-analysis. Ecology. 2012;93:930-8.

55. Barnard RL, Osborne CA, Firestone MK. Responses of soil bacterial and fungal communities to extreme desiccation and rewetting. ISME J. 2013;7:2229-41.

56. Van der Gucht K, Cottenie K, Muylaert K, Vloemans N, Cousin $\mathrm{S}$, Declerck S, et al. The power of species sorting: local factors drive bacterial community composition over a wide range of spatial scales. Proc Natl Acad Sci USA. 2007;104:20404-9.

57. Ranjard L, Dequiedt S, Prévost-Bouré NC, Thioulouse J, Saby $\mathrm{NP}$, et al. Turnover of soil bacterial diversity driven by wide-scale environmental heterogeneity. Nat Commun. 2013;4:1434.

58. Ricklefs RE, Lovette IJ. The roles of island area per se and habitat diversity in the species-area relationships of four Lesser Antillean faunal groups. J Anim Ecol. 1999;68:1142-60.

59. Hubbell SP. The unified neutral theory of biodiversity and biogeography. Princeton, New Jersey: Princeton University Press; 2001.

60. Smith GR, Steidinger BS, Bruns TD, Peay KG. Competitioncolonization tradeoffs structure fungal diversity. ISME J. 2018; $12: 1758-67$.

61. Chen J, Wang P, Wang C, Wang X, Miao L, Liu S, et al. Fungal community demonstrates stronger dispersal limitation and less 
network connectivity than bacterial community in sediments along a large river. Environ Microbiol. 2020;22:832-49.

62. Schmidt SK, Nemergut DR, Darcy JL, Lynch R. Do bacterial and fungal communities assemble differently during primary succession? Mol Ecol. 2014;23:254-8.

63. Norros V, Penttilä R, Suominen M, Ovaskainen O. Dispersal may limit the occurrence of specialist wood decay fungi already at small spatial scales. Oikos. 2012;121:961-74.

64. Adams RI, Miletto M, Taylor JW, Bruns TD. Dispersal in microbes: fungi in indoor air are dominated by outdoor air and show dispersal limitation at short distances. ISME J. 2013;7:1262-73.

65. Tisserat N, Kuntz JE. Dispersal gradients of conidia of the butternut canker fungus in a forest during rain. Can J Res. 1983;13:1139-44.

66. Liu J, Matthews TJ, Zhong L, Liu J, Wu D, Yu M. Environmental filtering underpins the island species-area relationship in a subtropical anthropogenic archipelago. J Ecol. 2020;108:424-32.

67. Wang Y, Bao Y, Yu M, Xu G, Ding P. Nestedness for different reasons: the distributions of birds, lizards and small mammals on islands of an inundated lake. Divers Distrib. 2010;16:862-73.
68. Peay KG, Kennedy PG, Talbot JM. Dimensions of biodiversity in the earth mycobiome. Nat Rev Microbiol. 2016;14:434-47.

69. Roy J, Mazel F, Sosa-Hernández MA, Dueñas JF, Hempel S, Zinger L, et al. The relative importance of ecological drivers of arbuscular mycorrhizal fungal distribution varies with taxon phylogenetic resolution. N Phytol. 2019;224:936-48.

70. Dray S, Pelissier R, Couteron P, Fortin MJ, Legendre P, Peres-Neto PR, et al. Community ecology in the age of multivariate multiscale spatial analysis. Ecol Monogr. 2012;82: 257-75.

71. Wang P, Li SP, Yang X, Zhou J, Shu W, Jiang L. Mechanisms of soil bacterial and fungal community assembly differ among and within islands. Environ Microbiol. 2020;22:1559-71.

72. Haddad NM, Brudvig LA, Clobert J, Davies KF, Gonzalez A, Holt RD, et al. Habitat fragmentation and its lasting impact on Earth's ecosystems. Sci Adv. 2015;1:e1500052.

73. Tong X, Zhang YX, Wang R, Inbar M, Chen XY. Habitat fragmentation alters predator satiation of acorns. J Plant Ecol. 2017; 10:67-73. 